\title{
Another wrinkle on the dual-task SRT experiment: It's probably not dual task
}

\author{
SIMON KI-YOUNG RAH and ARTHUR S. REBER \\ Brooklyn College, City University of New York, New York \\ and \\ ANDREW T. HSIAO \\ Moss Rehabilitation Institute, Philadelphia, Pennsylvania
}

\begin{abstract}
In the standard serial reaction time (SRT) experiment, subjects are required to respond rapidly to a structured sequence of visual targets. Evidence that subjects have acquired knowledge of the structure is obtained by modifying the structured nature of the sequence and noting whether reaction times increase. In the dual-task SRT experiment, a "secondary" tone-counting task is introduced, and the extent to which learning of the "primary" target sequence is compromised is noted. Here we present data that strongly imply that while the psychologists who designed this "dual-task" experiment may have viewed it this way, this may not be the best way to characterize it. The suggestion is that this "duality" is illusory and that we should probably be treating the tone-counting task as a potential source of additional patterns of covariation in a complex, multicomponent display and not as a "secondary," attention-diverting factor.
\end{abstract}

Just over a decade ago Nissen and Bullemer (1987) published a seemingly straightforward finding. In the serial reaction time (SRT) task, where subjects have to respond as quickly as possible to a repeating sequence of events, introducing an attention-demanding secondary task prevented learning of the target sequence. Since the SRT task is regarded by many as one of the better procedures for studying implicit learning, this finding attracted a great deal of attention and, not surprisingly, Nissen and Bullemer's initial conclusions were soon discovered to have been premature. Subsequent work (e.g., Cohen, Ivry, \& Keele, 1990; Reed \& Johnson, 1994, among many others) has shown that although an attentionally demanding secondary task certainly compromises performance, sequence learning can take place-but understanding the role that the secondary task plays has turned out to be an elusive goal (for a review of this research, see Hsiao \& Reber, 1998).

In the standard SRT procedure, subjects sit at a computer monitor on which is arranged some number of markers (usually four, but occasionally five or even six). A target stimulus (an * or other symbol) appears above one of the markers and subjects press the button on the keyboard that corresponds with that location as quickly as possible. After a short interval (usually about $200 \mathrm{msec}$ ), the next

This research was partially supported by a PSC-CUNY grant. We thank the denizens of the Institute for Experimental Epistemology for their (almost invariably) helpful contributions: Shahid Babar, Raquel Domgaard, Noam Fischman, Leib Litman, David Scaffidi, and Diane Zizak. Correspondence should be addressed to A. S. Reber, Department of Psychology, Brooklyn College of CUNY, Brooklyn, NY 11210 (e-mail: areber@ gc.cuny.edu). target occurs in a different location (repeating locations are typically not used in these experiments), again to be responded to by pressing the appropriate key. The sequence of events in most experiments follows a repeating pattern (e.g., Nissen \& Bullemer, 1987, used the sequence DBCACBDCBA), although in some studies a nonrepeating, rule-governed sequence is used (e.g., Cleeremans \& McClelland, 1991; Hsiao \& Reber, 1998; Jiménez, Mendez, \& Cleeremans, 1996). Blocks of roughly 100 trials are generally used with subjects run through some seven or eight blocks. Learning is assessed either by comparing subjects' reaction times (RTs) with those of a control group where the sequence is random or by transferring subjects to a single random block of trials and measuring the increase in RT. In the dual-task procedure, the typical secondary task is tone counting, in which each keypress is followed by either a high- or a low-pitched tone and subjects are required to keep a running count of one of them.

Although this procedure seems like a straightforward setting for exploring the role of attention in implicit learning, it has turned out to be more complex (and more interesting) than initially thought. Among the many issues raised by this research, the one that has attracted the most intense scrutiny is how, precisely, the imposition of the secondary tone-counting task compromises learning.

Several reasonable answers have been offered. Curran and Keele (1993), for example, argued that there are actually two learning mechanisms involved, one that requires attention and one that does not. Only the latter, they have maintained, is disrupted by the secondary task. On the other hand, Stadler (1995) has defended a single-mechanism process by arguing that the secondary task essentially disrupts the organization of the structural characteristics of 
the target sequence. Frensch and Miner (1994) presented data suggesting that the secondary task compromises learning by reducing available short-term memory needed to encode the target sequence. And recently, Frensch and his colleagues (Frensch, Lin, \& Buchner, 1998; Frensch, Wenke, \& Rünger, 1999) have put forward the novel proposal that the secondary task really only affects expression of what has been learned and not the learning itself.

Each of these proposals gives a plausible account of the basic phenomenon and each has some empirical support. However, they are all based on the assumption that there are two distinct tasks in these experiments and that the second, tone-counting task operates by compromising, in some fashion, performance on the primary, target-tracking task. However, this division into two tasks may not be warranted. The cognitive psychologists who run these studies may think that the to-be-detected covariations are those between the successive elements in the target sequence, but there is an alternative way of viewing this situation. The tone-counting task may degrade performance, not because it diverts attention, reduces short-term memory capacity, suppresses performance, and/or disrupts organization, but simply because it introduces a set of co-occurrences that have no predictive value.

One way of viewing implicit learning is that it is a nonselective processing system that routinely scans the environment for patterns of covariation (Cleeremans, 1993; Heuer \& Schmidtke, 1996; Reber, 1993; Saffran, Aslin, $\&$ Newport, 1996). Hence, the dual-task SRT experiment might better be viewed as one in which subjects are scanning for patterns of covariations between (1) successive targets, (2) successive tones, and (3) successive tonetarget pairs. If there is no structure in these latter two components - if the tone sequences are random and bear no relationship to the target locations - then the situation becomes one where the proportion of events in the environment that display patterns of covariation with predictive value is dramatically diluted. Detecting the co-occurrence that represent true covariations, thus, becomes more difficult.

Such a view, of course, makes sense only if subjects are actually processing these other features of the stimulus environment and are sensitive to covariations that may be present. Recently, Schmidtke and Heuer (1997) and Mayr (1996) presented evidence to suggest that the task may, in fact, be viewed as one having interlocking, interdependent components. Schmidtke and Heuer found that when the tone sequence also followed a repeating sequence, overall performance was enhanced, and, interestingly, when the two sequences were entrained (e.g., both Length 6), performance was better than if they were not (e.g., one Length 6, the other Length 5). The first finding suggests that subjects are encoding the tone sequence as well as the target sequence; the second implies that they may also be integrating the two. Mayr had both the location and the identity of the target object follow separate sequences and found that joint learning was as good as with a single sequence and, interestingly, that such joint learning emerged even when a tone-counting task was superimposed on the task.

These findings are intriguing but not conclusive. First, both Mayr (1996) and Schmidtke and Heuer (1997) modified the standard procedure. In Mayr's case, the two sequences were location and identity (different shapes appeared in different locations). Schmidtke and Heuer, rather than having subjects keep count of, say, high-pitched tones, had them press a foot treadle each time they heard a target tone. This procedural change is potentially a significant one since it dramatically reduces the role of shortterm memory in the "secondary" task. Their subjects needed only to detect which tonal event occurred on each trial; they were spared the much more demanding task of maintaining and updating an ongoing count of the number of particular tones that occurred. According to Frensch and Miner's (1994) interpretation, such a modification likely changes the nature of the task dramatically. In addition, the target sequences in Schmidtke and Heuer's studies were only six elements long, shorter than the sequences typically used in such experiments.

In this paper, we present data from four experiments in which the target and tone sequences have differing degrees of structure and differing degrees of mutual covariation. We maintained the standard procedure of requiring subjects to keep a running count of the number of either highor low-pitched tones, and we used repeated target sequences of Length 12. To anticipate, we found that even under these demanding conditions, individuals pick up the crossmodal patterns of covariation between the "primary" visual target sequences and the "secondary" auditory displays. Hence, subjects in these and many similar studies have likely been treating this dual-task, SRT experiment as a single-task experiment with multiple, integrative components.

We constructed four different sets of circumstances, each of which explores a different element of this dualtask situation. While these are, in some sense, separate experiments, we actually think of them more as demonstrations since each presents a circumstance under which subjects manifest an ability to integrate the two components of the procedure and develop a sensitivity to the patterns of covariation in the stimulus environment.

\section{GENERAL METHOD}

\section{The Display}

Subjects were seated at a computer. On the monitor was a picture of an open, grassy field with five molehills arranged in an arc. The targets were rather cute moles that popped up out of the molehills. Subjects had to press the key on the keyboard that corresponded to each mole; the keys: "z," "x," "space," ".," and "/" were used. Each mole stayed up out of the molehill until the correct key was pressed. A correct keypress was followed $150 \mathrm{msec}$ later by either a highpitched $(1000 \mathrm{~Hz})$ or a low-pitched $(200 \mathrm{~Hz})$ tone lasting $200 \mathrm{msec}$. Each subsequent target appeared $150 \mathrm{msec}$ after the tone terminated.

\section{The Targets}

The target sequence consisted of either a repeating 12-element sequence of locations, BDECEADCDABC, or a semirandom, nonrepeating sequence that was used in the transfer blocks. This nonre- 
peating sequence shared the same pattern of frequency of locations and first-order conditionals as the repeating sequence. We wish to emphasize these characteristics of the semirandom sequences since significant slowing of RTs under such transfer conditions shows that subjects in these experiments were learning at least second-order conditional relationships.

\section{Tones}

The tones were programmed so that they either contained information about the upcoming target location (contingent) or had no such predictive value (noncontingent). In a contingent condition, a low-pitched tone was followed by a target in Locations A, B, or C and a high-pitched tone by Locations $\mathrm{C}, \mathrm{D}$, or E. Hence, Locations $A$ and $B$ were uniquely predicted by high-pitched tones, $D$ and $E$ by low-pitched ones, and C could follow either. We will refer to tone sequences that follow these principles as "quasi-random." This arrangement was counterbalanced across subjects.

\section{Procedure}

Learning consisted of six blocks of 120 trials each. During this phase, the target sequence could be either a repeating or a nonrepeating target sequence and the tones could be either contingent or noncontingent. Block 7 was always a transfer block where some aspect of the multiple contingencies manifested during learning was no longer present. In Block 8 the relationships present during learning were restored.

\section{Instructions}

Subjects were instructed to press the appropriate key to the target location as rapidly and accurately as possible. They were also asked to keep a running count of one of the tones (e.g., the high-pitched) in each block of trials and record the final count at the end of that block. No mention was made of the existence of the repeating sequence or the target-tone contingencies.

\section{Data}

The essential data are the RTs to the moles. Because of the high variance in these studies, all analyses were carried out using the median RT of each subject for each cycle of the sequence and then calculating the mean of those medians for the block. The critical comparison for demonstrating learning was Block 7 against the mean of Blocks 6 and 8 . We used this procedure because it is clear that learning was not complete by the end of Block 6 . Hence, the difference between Block 7 RTs and those on both Blocks 6 and 8 gave a measure of the extent to which disrupting the relationships between the targets and the tones compromised performance.

Subjects whose error rate on the tone-counting task was greater than $10 \%$ were eliminated from the standard analyses, as were those whose error rate to the target moles was greater than $5 \%$. There are reasons to believe that these individuals were treating the task very differently from those who were paying attention to both aspects of this experiment (Hsiao, 1997; Hsiao \& Reber, 1998), and below we will present additional data that support this contention.

\section{EXPERIMENT 1}

\footnotetext{
Method

Target-tone arrangement during learning. The target sequence was a semirandom, nonrepeating sequence. The tone sequence was quasi-random but contingent. Thus information about target location could be gathered only by detecting the tone-target relationship.

Block 7 transfer. The target location continued to be semirandom but the tone-target contingency was eliminated. The design for this experiment is given schematically in Table 1 , where it can be easily compared with the variations that will follow in the next three experiments.
}

Table 1

\begin{tabular}{|c|c|c|}
\hline Phase & Target Sequence & Tone Sequence \\
\hline $\begin{array}{l}\text { Experiment } 1 \\
\text { Learning (Blocks 1-6,8) } \\
\text { Transfer (Block 7) }\end{array}$ & $\begin{array}{l}\text { Semirandom } \\
\text { Semirandom }\end{array}$ & $\begin{array}{l}\text { Contingent } \\
\text { Noncontingent }\end{array}$ \\
\hline $\begin{array}{l}\text { Experiment } 2 \\
\text { Learning (Blocks 1-6,8) } \\
\text { Transfer (Block 7) }\end{array}$ & $\begin{array}{l}\text { Repeating } \\
\text { Repeating }\end{array}$ & $\begin{array}{l}\text { Contingent } \\
\text { Noncontingent }\end{array}$ \\
\hline $\begin{array}{l}\text { Experiment } 3 \\
\text { Learning (Blocks 1-6, 8) } \\
\text { Transfer (Block 7) }\end{array}$ & $\begin{array}{l}\text { Repeating } \\
\text { Semirandom }\end{array}$ & $\begin{array}{l}\text { Contingent } \\
\text { Noncontingent }\end{array}$ \\
\hline $\begin{array}{l}\text { Experiment } 4 \\
\text { Learning (Blocks 1-6,8) } \\
\text { Transfer (Block 7) }\end{array}$ & $\begin{array}{l}\text { Repeating } \\
\text { Semirandom }\end{array}$ & $\begin{array}{l}\text { Noncontingent } \\
\text { Noncontingent }\end{array}$ \\
\hline
\end{tabular}

Note--Repeating target sequences followed the repeating pattern given in the General Method section. Semirandom target sequences were random with the constraint that locations could not repeat; when used during transfer, zero- and first-order conditionals match those of the learning sequence. In contingent tone sequences, each tone has predictive value for the upcoming target, as described in the General Method section. Noncontingent tone sequences were random with no constraints, and the tones had no predictive value.

Subjects. The subjects were 20 undergraduates at Brooklyn College who were fulfilling a requirement of introductory psychology.

\section{Results and Discussion}

The mean RT for Block 7 was 635 msec. The mean of Blocks 6 and 8 was $612 \mathrm{msec}$. This difference was significant $[t(19)=2.80, p=.01]$. Hence, even though the target sequence was unstructured, subjects were picking up on the contingency between each successive target and the pitch of the tone that immediately preceded it, since when this contingency was removed, performance was significantly degraded. The clear implication is that in these dualtask situations subjects are likely scanning for and capable of detecting patterns of covariations between the two components of the stimulus display.

\section{EXPERIMENT 2}

\section{Method}

Target-tone arrangement during learning. The target sequence was the repeating sequence; the tones were quasi-random but contingent. Thus, both the repeating nature of the target sequence as well as the tone-target contingency can be used to support performance.

Block 7 transfer. The repeating sequence continued but the tonetarget contingency was eliminated.

Subjects. The subjects were 22 undergraduates at Brooklyn College who were fulfilling a requirement of introductory psychology.

\section{Results and Discussion}

The mean RT for Block 7 was $668 \mathrm{msec}$. The mean of Blocks 6 and 8 was $643 \mathrm{msec}$. This difference was significant $[t(21)=2.20, p=.04]$. This finding is a nice adjunct to the preceding. The tone-target relationships were still being used to support behavior, and even though subjects were sensitive to the repeating nature of the "primary" target sequence, they were also sensitive to the dual contin- 
gency, since removing the tone-target support significantly degraded performance.

\section{EXPERIMENT 3}

\section{Method}

Target-tone arrangement during learning. As in the preceding condition, subjects worked with both the repeating sequence and contingent tones.

Block 7 transfer. The sequence became semirandom; the tonetarget contingency was maintained.

Subjects. There were 19 subjects from the same pool.

\section{Results and Discussion}

The mean RT for Block 7 was $675 \mathrm{msec}$; that for Blocks 6 and 8 was $630 \mathrm{msec}$. Again, this difference was significant $[t(18)=2.42, p=.027]$. This finding is rather intriguing. It suggests that although we know from Experiment 2 that the tone-target contingency is playing a role in these experiments, by itself it is not sufficient to maintain performance in a context where a repeating sequence had previously been in place.

\section{EXPERIMENT 4}

\section{Method}

Target-tone arrangement during learning. The targets followed the repeating sequence; the tones were purely random and noncontingent. This procedure is, in essence, the condition that has been used in the traditional dual-task SRT study where there is a repeating target sequence and there is no support from the secondary tone sequence.

Block 7 transfer. The sequence became semirandom; the tones continued to be random and noncontingent.

Subjects. There were 20 subjects from the same pool.

\section{Results and Discussion}

The mean RT for Block 7 was $639 \mathrm{msec}$; that for Blocks 6 and 8 was $625 \mathrm{msec}$. This difference, unlike those in the previous conditions, was not significant $[t(19)=1.18, p=$ .25]. This result suggests that under these rather difficult experimental conditions, one does not necessarily see learning without support from the tone-target contingency.

This finding is of some concern, for it raises the possibility that we have been studying something other than how sequence learning relates to a "secondary" task because there may be no sequence learning. Were this true, our arguments ring rather hollow. The question we need to ask, then, is whether or not the sequence we used in these studies is learned under single-task conditions.

\section{EXPERIMENT 4A}

\footnotetext{
Method

Subjects. There were 6 subjects from the same pool. These subjects were, in fact, those who participated in Experiment 4 but who were dropped from the analysis because of failure to meet criterion on the counting task. Elsewhere (Hsiao, 1997) it has been demonstrated that subjects who are not counting accurately are, in fact, not devoting attentional resources to the secondary task. They are statistically indistinguishable from subjects who are either (1) in a single-
}

task experiment or (2) merely asked to estimate how many target tones they thought they heard in each trial block.

\section{Results and Discussion}

The mean RT for Block 7 was $624 \mathrm{msec}$; that for Blocks 6 and 8 was $566 \mathrm{msec}$. This difference was significant $[t(5)=$ $1.96, p=.05]$. These subjects clearly showed sequence learning. In fact, their mean RT for Blocks 6 and 8 was far below that for any other experiment and far below that for the subjects who satisfied the counting criterion. Hence, we are comfortable concluding that we have, indeed, been exploring the same task as all of our colleagues who have been intrigued by the psychological processes that underlie performance on the SRT procedure.

\section{GENERAL DISCUSSION}

The message seems quite straightforward. In so-called dual-task SRT studies, the "secondary" tone-counting task may be profitably viewed, not as some "other," invasive element that compromises learning of a "primary" task, but as an integral component of a complex stimulus environment. If the process of implicit learning is anything like the characterization provided by such theorists as Cleeremans (1993) and Reber (1993), these findings should come as no surprise. Both Cleeremans and Reber have viewed implicit learning as the detection and representation of patterns of covariation manifested in the environment. Additional support for this point of view comes from recent work by Saffran and her colleagues (Saffran, Newport, Aslin, Tunick, \& Barrueco, 1997), who have shown that such pickup of the statistical features of a complex display can also take place under incidental conditions. In their study, subjects focusing on a fairly demanding visual task implicitly developed a sensitivity to auditory patterns played in the background.

The original designers of the dual-task SRT experiments may have thought of the tone-counting task as somehow "separate" from the core environment, but it is unlikely that the subjects in these studies have been treating it as such. Our findings, along with those of Schmidtke and Heuer (1997) and Mayr (1996), suggest that the experiment should probably be thought of as one involving a complex environment with a variety of interacting domainsany of which could potentially be characterized by genuine patterns of covariation among the detectable elements and all of which need to be (implicitly) scanned. The reason the "secondary" task compromises performance on the "primary" task is likely due simply to the fact that the "secondary" tasks used have been noncontingent. It is worth noting that this picture of implicit learning fits comfortably with contemporary views of Pavlovian conditioning (see Miller, Barnet, \& Grahame, 1995; Rescorla, 1988; Rescorla \& Wagner, 1972).

Finally, Schmidtke and Heuer's (1997) conclusion that it is the integration of the auditory and the visual stimulus streams that is the critical factor in these experiments, while not wrong, should probably be rephrased. The key 
is not that subjects are necessarily integrating the two sequences but rather that they are scanning the environment for potentially coordinate patterns of covariation. When the various components are coordinate because there is some measure of predictive validity between them, we will see the kinds of patterns of response coordination observed in these experiments. Integration may be a component of such multichannel implicit learning but it is not necessarily an essential feature. Saffran et al.'s (1997) results suggest that such learning also takes place when the "secondary" sequence is presented as an incidental stimulus stream with no integrative relationship to the subjects' primary task.

\section{REFERENCES}

Cleeremans, A. (1993). Mechanisms of implicit learning: Connectionist models of sequence processing. Cambridge, MA: MIT Press.

Cleeremans, A., \& McClelland, J. L. (1991). Learning the structure of event sequences. Journal of Experimental Psychology: General, $120,235-253$.

Cohen, A., Ivry, R. I., \& KeEle, S. W. (1990). Attention and structure in sequence learning. Journal of Experimental Psychology: Learning, Memory, \& Cognition, 16, 17-30.

Curran, T., \& KeEle, S. W. (1993). Attentional and nonattentional forms of sequence learning. Journal of Experimental Psychology. Learning, Memory, \& Cognition, 19, 189-202.

FrensCh, P. A., Lin, J., \& BUCHNER, A. (1998). Learning versus behavioral expression of the learned: The effects of a secondary tonecounting task on implicit learning in the serial reaction time task. Psychological Research, 61, 83-98.

FrensCh, P. A., \& Miner, C. S. (1994). Effects of presentation rate and individual differences in short-term memory capacity on an indirect measure of serial learning. Memory \& Cognition, 22, 95-110.

FrensCh, P. A., WenKe, D., \& RüNGER, D. (1999). A secondary tonecounting task suppresses performance in the serial reaction task. Journal of Experimental Psychology: Learning, Memory, \& Cognition, 25, 260-274.

Heuer, H., \& Schmidtke, V. (1996). Secondary-task effects on sequence learning. Psychological Research, 59, 176-186.

HsiaO, A. (1997, April). Implicit sequence learning depends on avail- able residual attention. Paper presented at the annual meeting of the Eastern Psychological Association, Washington, DC.

Hsiao, A., \& REBER, A. S. (1998). The role of attention in implicit sequence learning. In M. A. Stadler \& P. A. Frensch (Eds.), Handbook of implicit learning (pp. 471-494). Thousand Oaks, CA: Sage.

Jiménez, L., MendeZ, C., \& Cleeremans, A. (1996). Comparing direct and indirect measures of sequence learning. Journal of Experimental Psychology: Learning, Memory; \& Cognition, 22, 948-969.

MAYR, U. (1996). Spatial attention and implicit sequence learning: Evidence for independent learning of spatial and nonspatial sequences. Journal of Experimental Psychology: Learning, Memory, \& Cognition, 22, 350-364.

Miller, R. R., Barnet, R. C., \& Grahame, N. J. (1995). Assessment of the Rescorla-Wagner model. Psychological Bulletin, 117, 363-386.

NisSEN, M. J., \& Bullemer, P. (1987). Attentional requirements of learning: Evidence from performance measures. Cognitive Psychology, 19, 1-32.

REBER, A. S. (1993). Implicit learning and tacit knowledge: An essay on the cognitive unconscious. New York: Oxford University Press.

REED, J., \& JOHNSON, P. (1994). Assessing implicit learning with indirect tests: Determining what is learned about sequence structure. Journal of Experimental Psychology: Learning, Memory, \& Cognition, 20, 585-594.

RESCORLA, R. A. (1988). Pavlovian conditioning: It's not what you think it is. American Psychologist, 44, 151-160.

ResCoRLA, R. A., \& WAGNER, A. R. (1972). A theory of Pavlovian conditioning: Variations in the effectiveness of reinforcement and nonreinforcement. In A. H. Black \& W. F. Prokasky (Eds.), Classical conditioning II: Current research and theory (pp. 64-99). New York: Appleton-Century-Crofts.

Saffran, J. R., Aslin, R. N., \& Newport, E. L. (1996). Statistical learning by 8-month-old infants. Science, 274, 1926-1928.

Saffran, J. R., NewPort, E. L., Aslin, R. N., Tunick, R. A., \& BarRUECO, S. (1997). Incidental language learning: Listening (and learning) out of the corner of your ear. Psychological Science, 8, 101-105.

SCHMidTKE, V., \& HeuER, H. (1997). Task integration as a factor in secondary-task effects on sequence learning. Psychological Research, 60, 53-71.

STADLER, M. A. (1995). Role of attention in implicit learning. Journal of Experimental Psychology: Learning, Memory, \& Cognition, 21, 819-827.

(Manuscript received May 12, 1999; revision accepted for publication June 15, 1999.) 